\title{
NUEVOS DOCUMENTOS REFERENTES A DON LUIS DE GONGORA Y ARGOTE
}

Cuando en $x 927$ se celebró el tercer centenario de la muerte del ilustre cordobés, la Real Academia de Córdoba le dedicó un número extraordinario de su Boletin, en el que, aparte de recoger los actos celebrados, se insertaron unos trabajos eruditos de distintos académicos, estudios sobre la personalidad de don Luis bajo diferentes aspectos. Uno de ellos, como es bien sabido, fue la aportación de cien documentos inéditos sobre el racionero-poeta y su familia, debido al nunca bien llorado don José de la Torre y del Cerro.

Con posterioridad el señor La Torre encontró otros que no llegó a publicar. Siguiendo las huellas por él trazadas, me fue dado hallar otros, en mi modesto trabajo de investigación, en el Archivo Histórico Provincial de Córdoba, que, por insinuación del ilustre gongorista don Dámaso Alonso, me es grato ofrecer a los interesados de esta clase de estudios.

No vamos a caer en la pedantería de creer que son de importancia capital en la biografía de don Luis; su único interés estriba en ir llenando los clatos que, en algunos años, quedaron en la relación de escrituras notaiiales otorgadas por el inmortal poeta.

En alguno de ellos, como en otros ya conocidos, es desconsolador ver a nuestro poeta, ya en un año, ya en otro, declararse deudor de cantidades recibidas, indispensables para sostener con decoro su rango señorial. Pero él, con tesón admirable, va soslayando los reveses económicos y cimentando, cada vez con mayor fuerza, su nombre al lado de los grandes oráculos de su tiempo. Todas estas circunstancias, capaces de abatir a cualquier espíritu, no consiguen sumirle en el anonimato. Si de momento su nombre no atrae el respeto y admiración a que es acreedor, llegaría el día en que su fama llenaría de gloria la literatura patria y enriquecería la universal.

Entre los cien documentos mencionados aparece uno, señalado con el número 87 , de fecha 16 de febrero de 1612 , en el que don $I_{1}$ uis otorga 
un pcder a su sobrino don Luis de Saavedra para que arriende, por la vida de ambo:, del deán y cabildo, unas casas en la collación de Omnium Sanctorum, que fueron las que habitó en sus últimos años y en la; que murió.

La cosa en sí tiene el alto valor histórico de ubicar la última morada terrena del cordobés insigne. Dichas casas eran propias de la Mesa Capitular, que las había habido por manda que de ellas hizo al Cabildo el licenciado Juan de Mora, presbítero y capellán que había sido de la capilla de San Acacio, también llamada de la Sangre, en la catedral, el que igualmente hizo donación de otros objetos a la Corporación eclesiástica; entre ellos, un portapaz, que se conserva en el tesoro, y un Ecce-Homo, que se venera en el retablo de la mencionada capilla.

De los que hoy se publican, el último de ellos, hace referencia al mismo asunto de la casa. Es otro poder de don L uis otorgado en favor del expresado sobrino, con el mismo objeto y fecha, pero ante distinto escribano. Cotejados ambos documentos, nada se diferencian en su contenido general: es decir, en la fórmula común utilizada en esta clase de escrituras, como el tiempo del arrendamiento, precio, linderos, etc.

Sin embargo este último es más explícito en determinar el emplazamiento de la casa, pues ya no lo hace generalizando dentro de la colación, sino indicando ser en la plazuela del convento de la Santísima Trinidad y añadiendo medio par de gallinas a los treinta y siete obligados a dar en los plazos y señales tradicionales.

Sea como quiera, ahí quedan ambas escrituras del arrendamiento de la casa donde el insigne vate vivió por espacio de quince años, últimos, de entre los de su vida fecunda, que tardaría después no pocos en merecer la atención y estudio de su contenido, para proclamar la excelsitud de su obra y colocarse en el sitio de privilegio a que era acreedor por su numen de excepción.

Rafaei Aguilar Priego.

\section{DOCUMENTO NUMERO I.}

ESCRITURA otorgada por don Luis de Góngora, a favor de Juan Sánchez Martinez, del recibo de ciertas cantidades de frutos que le pertenecian de la pretamera de Santaella.

Córdoba, Io de Marzo de 1593

Sepan quantos esta carta bieren cómo en la çiudad de Cordoba, diez dias del mes de março de myll e quinientos noventa e tres años, otorgó don Luys de Gongora, raçionero en la santa yglesia de Cordoba, que a reçibido de Juan Sanchez Martinez; vecino de Cordoba, quatro çientas dos fanegas de trigo e tres çelemines de trigo e çiento e noventa e quatro fanegas de çebada, que al otorgante le cupo, el año 
pasado, de myll e quinientos e noventa e dos, por raçon de los frutos de la prestamera que posee en la villa de Santaella, por repartimiento del notario de rentas, lo qual el dicho Juan Sanchez Martines cobro en virtud de çierto poder y cesion en causa propia, quel otorgante le dio e otorgo en la escriptura de yndemnidad quel otorgante $y$ otros, con el obligados, otorgaron en favor de dicho Juan Sanchez Martinez y de Pedro Toledo, vecinos desta çiudad, en raçon de la fiança y obligaçion que hiçieron a el dicho don Luys en el censo que bendio e ympuso sobre sus bienes en fabor de la capellania que, en la yglesia de Santiago de Cordoba, fundo el jurado Francisco Valdelomal, en cantidad de quinientos e quarenta e vn ducados de principal, el qual dicho trigo e cebada el dicho Juan Sanchez Martines bendio: el trigo, a catorçe reales, y la cebada, a seys reales, que, a los dichos preçios, monto seys myll e setençientos e noventa e nuebe reales, y de caussas de quel dicho don Luis de Gongora a tenido neçesidad de la dicha cantidad, el dicho Juan Sanchez Martinez se los a entregado, y el dicho don Luys de Gongora confeso aberlos reçibido en esta manera: quinientos e çinquenta reales, por mano de don Gonçalo de Saabedra, difunto; duçientos reales el dicho don Luys, en veinte e dos de julio de noventa e dos; sesenta e quatro reales, en costas de recoxer el pan; tres mill reales a el dicho don Luys, por çedula, en siete de nobienbre de nobenta e dos; a Juan Clavixo, criado del otorgante, por çedula de don Francisco de Argote, su padre, nobeçientos y ochenta reales; a Juan Castro, jurado de Cordoba, por çedula del dicho don Francisco, setecientos reales, que las dichas partidas montan çinco myll y quatroçientos e nobenta e quatro reales, los quales, sacados de los dichos seys myll y seteçientos e nobenta e nuebe reales, quedan myll e tresçeintos e çinco reales; los dichos myll e tresçientos reales reçibio de presente el dicho Juan Sanchez Martinez, con que queda enteramente pagado de las dichas quatroçientas e dos fanegas e tres çelemines de trigo y çiento e nobenta e quatro fanegas de çebada; de todo se otorgo entregado a su boluntad, renunçio la excecuçion de la cosa no bista, leyes e derechos paga e prueba, y de las dichas quatroçientas e dos fanegas e tres celemines de trigo y ciento y nobenta e quatro fanegas y ocho celemines de cebada e marabedies que dellas an proçedido, dio por libre a el dicho Juan Sanchez Martinez y otorgo carta de pago e finiquito bastante, que se obligo de aber por firme, so pena de duçientos myll marabedies pagado, e no que valga lo dicho, e para cumplillo, obligo asi y a sus bienes, e dio poder a las justicias para su ejecucion, como por sentecia pasada en cosa juzgada, e se declara quel poder e çesion en causa propia en esta escriptura referido e otorgado por la dicha escriptura de yndinidad por el dicho don Luis, y los demas con el obligados, en favor de los dichos Juan Sanchez Martinez e Pedro de Toledo, que passo ante el escribano de yuso escrito. en trece dias del mes de nobiembre del año de myll e quinientos / a nobenta e vn años, la dicha yndinidad e poder por ellos otorgado a el dicho Juan Sanchez Martines, no se altera ni ynoba, en todo ni en parte, por aber benido a pagar los frutos de la dicha prestamera del dicho año de nobenta e dos a poder del otorgante, antes se aprueba e retifica en los frutos de la dicha prestamera deste presente año de nobenta $\mathrm{y}$ tres y los demas adelante benideros hasta que tenga efeto la quenta e redinçi on del dicho çensso, renta e prinçipal del, y que los dichos Juan Sanchez Martin ez e Pedro de Toledo se hagan libres de la fiança e obligacion que en el hiçieron a el dicho don Luys de Gongora, y lo abra por firmes, debaxo de la obligacion e ejecucion y poder a las justicias ante escriptas, y. lo firmo de su nombre el otorga nte, a quien yo, el escribano, doy fee que conozco, siendo testigos Francisco del Canpo y Luys de Perea y Francisco de Salzedo, moradores en Cordoba y fir- 
molo el otorgante, que yo, el escribano, conozco; entre renglones tres myll. D. Luys de Gongora (rubricado), Alonso Rodriguez de la Cruz (rubricado y signado). Derechos dos reales. Llelvado.

Archivo de Protocolos de Córdoba.

Oficio, 22

Protocolo, 43

Folio, 473

\section{DOCUMENTO NUMERO $z$}

Poder otorgado por don Luis de Góngora a favor de Bartolomé Gutiérrez Bustos, para la cobranza de los frutos del diezmo de Guadalmazán.

Córdoba, ro de Marzo de 1593

PODER/Sepan quantos esta carta de poder vieren cómo yo, don Luis de Gongora, rraçionero en la. Santa Yglesia de Cordova, conozco y otorgo que doy todo poder cumplido en derecho bastante a Bartolome Gutierrez Bustos, vezino desta ciudad, mostrador desta carta, para que, por my y en mi nonbre, e como yo mysmo, e para el y en su causa propia, demande, rreciba e cobre, asin en juicio como fuera del, de los arrendadores, fieles y corredores y otras personas a cuyo cargo / es e fuere, el diezmo del bino de Guadalmazan, frutos del año de myll e quinientos e nobenta e dos, diez myll y tresçientos e quarenta maravedis, que me cupo en el arrendamiento del dicho diezmo por razon de my prestamera por repartimiento de notario de rrentas dellos, dé carta de pago, rrecibo y lastro y finiquito, balgan como si yo las diese en la cobranza, parezca en juicio y haga los autos judicilaes y estrajudiciales, juramentos e diligencias que conbengan en mys derechos y alciones rreales y personales y executibos para que los cobre para si, por razón y a quenta de mayor contia que yo le debo sobre que en la dicha cantidad ............necesario me otorgo por entregado, rrenuncio la ecesçion de la cosa no bista, leyes e derechos de la paga e prueba, y me obligo de aber por firme este poder y no lo rrebocar, so pena de dies myll maravedis pagado, o no que balga lo dicho, y para cunplillo obligo a my y a mys bienes y doy poder a las justicias para su ejecución, como por sentencia pasada en cosa juzgada, fecha y otorgada esta carta en Cordova, diez dias del mes de março de myll e quinientos e noventa e tres años, siendo testigos Juan de Clabixo e Juan de Ribera y Francisco del Campo, notario, vezinos de Cordova y del otorgante, a quien yo, el escriuano, doy fee que conozco, lo firmo de su mano en el rregistro. D. I uis de Gongora (rubricado) - Alonso Rodriguez de la Cruz escribano publico (signado y rubricado) Derechos un real - Llevado.

Archivo de Protocolos de Córdoba.

Oficio, 22

Protocolo, 43

Folio, 475 V. 


\section{DOCUMENTO NUMERO 3}

Obligación otorgada por don Luis de Góngora a favor de Martin Fernández de Ribera para pagarle 700 reales que le prestó.

Córdoba, 7 de Julio de 1593

O B L IGACION/Sepan quantos esta carta vieren cómo yo don Luis de Gongora, rraçionero en la Santa Yglesia de Cordoba, vecino que soy de la dicha ciudad en la collaçion de san Bartolone, otorgo y me obligo de dar y pagar a M1guel Fernandez de Ribera, vecino desta çiudad, questa presente, sieteçientos reales de a treynta y cuatro maravedis por rreal, que me presto por me hacer plaçer, los quales dichos seteçientos reales rreçebi del dicho Miguel Fernandez. rrealmente y con efeto, en reales de plata con dos doblones de oro a ochoçientos maravedis cada vno, rrealmente y con efeto, ante el escribano y testigos que me los bieron rrecebir, del qual entrego y rreçibo de los dichos seteçientos rreales, yo, el escribano, doy fee y de ellos yo, el dicho don Luis de Gongora, me otorgo por entregado a mi boluntad, otorgo y me obligo de los dar y pagar al dicho Miguel Fernandez en trigo por el dia de Nuestra Señora de setienbre que berna del año de mill y quinientos y nobenta y quatro, en trigo a como baliere en esta ciudad el dicho dia de Nuestra Señora de setienbre, ocho dids antes o despues, con que el dicho preçio no eçeda del coto puesto por su Magestad, el dicho preçio quede liquidado con dos testigos de ynformaçion sumaria, y todo lo cumpliere sin pleyto. so pena del derecho, y, por aquel dicho Miguel Fernandez de Ribera mas çierto sea del cunplimiento desta carta, le doy poder cunplido para que, liquidado el dicho preçio, pueda rreçebir y cobrar la cantidad de trigo que montaren los dichos seteçientos reales al preçio que se liquidaren conforme a esta escriptura, del mayordomo ques e fuere de la mesa capitular de la dicha Yglesia, del trigo quel dicho año perteneçiere a mi, el dicho otorgante, el dicho año, por rraçón de la dicha mi rraçion, que fueren a cargo del dicho mayordomo dellos, dé carta de pago, rreçibo y lastro, valgan como si yo las diese en la cobrança, parezca en juiçio y haga los autos judiçiales y extrajudiçiales que conbengan, en que le rrenunçio mys derechos $\mathrm{y}$ açiones rreales $\mathrm{y}$ personales $\mathrm{y}$ exeçutibos, por la dicha rraçon pueda el dicho Martin Fernandez vsar del vn rremedio y del otro y de anbos juntamente hasta que con el efeto cobre y abre por firme esta carta, y no rrebocare este poder, so pena de çinquenta mill maravedis pagados, e no que balga lo dicho, $y$, para cunplillo, obligo mi persona y bienes $\mathrm{y}$ dio poder a las justiçias para que la premien a su ejecucion y cunplimiento, como por sentençia pasada en cosa jusgada, y rrenunçio el capitulo duardus de disiluçiones, que trata sobre el alimento de los clerigos y la general, y yo, el dicho Martin Fernandez, que soy presente, esta escritura / açeto y rrecibo en mi fabor, la qual es fechà y otorgada en la dicha çiudad de Cordoba, a siete dias del mes de jullio de mil y quinientos y noventa y tres años, siendo testigos don Juan de Gongora y de Argote, veinticuatro de Cordoba, y Luis de Perea, criado del otorgante, y Marcos Ruiz, vecinos y moradores en Cordoba, y firmolo de su nonbre el otorgante, que yo, el escribano, conozco. Don Luis de Gongora (rubricado) - Alonso Rodriguez de la Cruz escribano publico (signado y rubricado) Derechos, dos reales. Llevado.

Archivo de Protocolos de Córdoba.

Oficio, 22

Protocolo, 43

Folio, r.194 vt. ${ }^{\circ}$ 


\section{DOCUMENTO NUMERO 4}

Escritura otorgada por Don Luis de Góngora, racionero en la Santa Iglesia de Córdoba, dando en administración los frutos que le pertenecian de la prestamera de Santaella a Gaspar Sánchez Lobo, por tiempo de tres años.

\section{Córdoba, I I de Julio de 1594}

MAYORDOMIA / Sepan quantos esta carta vieren cómo en la muy noble y muy leal ciudad de Cordova, honce dias del mes de jullio de mill y quinientos y noventa e quatro años, otorgaron, de la una parte, don Luis de Gongora, rraçionero en la Santa Yglesia de Cordova y veçino della, y de la otra, Gaspar Sanchez Lobo, veçino de la dicha çiudad, anbos en la collaçion de Santa Maria, anbas las dichas partes dixeron que ansi quel dicho Gaspar Sanchez Lobo toma a su cargo, por el dicho don Luis de Gongora, cobrar, benefiçiar y administrar todos los frutos de pan y maravedis, menudo, bino y aceyte y otros qualesquier de la prestamera quel dicho rraçionero don I uis de Gongora tiene y posee en la billa de Santaella deste obispado, por el tienpo de tres años enteramente, que son este presente año de mill y quinientos y nobenta e quatro y los años que bernan de mill y quinientos y nobenta $y$ çinco y seis, en la qual dicha mayordomia e administraçion el dicho Gaspar Sanchez Lobo se obligo de guardar e cunplir las condiçiones siguientes.

Primeramente, que todo el pan, trigo y cebada y otras semillas perteneçientes a la dicha prestamera en el dicho tienpo de tres años, el dicho Gaspar Sanchez Lobo a de ser obligado y se obligo de lo cobrar en silos o en camaras en la dicha villa, las costas de la cobrança e camaraxe an de ser por quenta de la misma haçienda, $y$, en lo que toca a el pan, trigo y cebada y otras semillas frutos deste presente año, lo a de poder bender el dicho Gaspar Sanchez Lobo por el dia de la Nabidad primero que berna fin deste dicho presente año, sin lo comunicar con el dicho don Luis, a el preçio questonçes baliere en la dicha villa, con que no eçeda del coto puesto por Su Magestad, y avnque no llegue a el dicho preçio de coto, el qual preçio se a de liquidar con dos testigos de ynformaçion sumaria, hecha de pedimento del dicho Gaspar Sanchez Lobo, sin que para ello preçeda ninguna çitaçion, auto ni aberiguaçion, avnque de derecho se rrequiera, y este dicho primero de año y en los dos años vitimos y en todos tres años, y en qualquiera dellos, llegando el dicho pan, trigo y cebada a baler el coto de Su Magestad, el dicho Gaspar Sanchez Lobo a de disponer dello sin aguardar consentimiento del dicho don Luis por que, en el caso susodicho, desde luego, el dicho don Luis presta el dicho consentimiento y en los dichos dos años vitimos si, a el tienpo de la cosecha, el dicho pan, trigo y çebada baliese a el preçio del coto, en el caso suso dicho lego Gaspar Sanchez Lobo a de ser obligado y se obligo de ensilar o en camaras en la dicha villa o en su termino, el dicho pan, trigo, cebada hasta tanto que balga el dicho preçio del coto, $y$, abiendose de vender a menos quel dicho preçio del coto, a de ser comunicandolo con el dicho don Luis y precediendo su boluntad y consentimiento, y por que, conforme a esta escritura, en los dichos dos años vitimos desta mayordomia y administraçion no baliendo el dicho pan, trigo y çebada, a el tienpo de la cosacha, el coto, se a de guardar hasta que balga el dicho preçio del coto, hasta quel dicho don Iuis preste consentimiento se benda a menos a como baliere el dia del tal consentimiento, si, a este tienpo, estando el dicho pan, trigo y cebada en los 
dichos silos o encamarado, se tomase o enbargare todo o parte dello por mandato de Su Magestad para el serbiçio se sus armadas o galeras o por otro qualquier ministerio o por qualquier / juez o conzejo o en otra manera, o en los silos o camaras se moxare el dicho pan, trigo o cebada por arroyo o gotera o por qualquier causa, o le suçediere gorgoxo o otro daño, el rriesgo o daño que sobre el suso dicho o sobre qualquier cosa dello sucediere a el dicho pan, trigo y cebada, a de ser por quenta del dicho don Luis de Gongora, y no del dicho Gaspar Sanchez Lobo, lo mismo se entienda si, estando el dicho pan, trigo y cebada ensilado se........ tare, con que, encamarándose el dicho pan, trigo y çebada en la dicha villa de Santaella, la persona a quien el dicho Gaspar Sanchez lo entregare enguarda y deposito, atento quel dicho Gaspar Sanchez le a de nonbrar, del rriesgo que en este caso obiere, a de ser por quenta del dicho Gaspar Sanchez Lobo, y por que, como dicho es, todas las costas que se hiçieren en el dicho ençierro y camaraxe y mas costas que se hiçieren en la cobranca e beneficio de los dichos frutos, todo a de ser por quenta de la misma haçienda, se declara se le an de rreçebir en quenta de dichos gastos a el dicho Gaspar Sanchez por la declaraçion y cartas de pago de las personas que las vbieren de aber y rreçibieren juntamente con la declaraçion y juramento del dicho Gaspar Sanchez Lobo.

Iten las partidas quel dicho Gaspar Sanchez Lobo no cobrare y rreçibiere, se le an de rrecebir en quenta con las diligençias quel hiçiere, las quales diligençias a de començar en tienpo y proseguillas por los terminos de derecho.

Yten que del balor de los dichos frutos el dicho Gaspar Sanchez Lobo pague a las personas y las contias siguientes, a Pedro de Bides, veçino desta ciudad, sesenta e çinco mill y quatroçientos y seis marabedis, quel dicho don Luis de Gongora le debe por quenta entre anbos, a pagar el dia de Nuestra Señora Santa Maria de Agosto primcro deste presente año.

Yten pague a Oraçio Castaño, rresidente en Cordova, quarenta y siete mill y seisçientos maravedis, quel dicho don Luis de Gongora le debe, a pagar el dicho dia de Santa Maria de Agosto primero.

Yten pague a Hernando Alonso, escribano de su Magestad, vecino de Cordova, seisçientos rreales, quel dicho don Luis le debe, a pagar el dia de Nabidad primero.

Yten pague a Alonso Diaz de la Cruz, veçino de Cordova, quatroçientos rreales, quel dicho don Luis de Gongora le debe, a pagar el dicho dia de Nabidad primero, que las dichas quatro partidas suman y montan çiento y quarenta y siete mill $y$ seis maravedis.

Yten pague, en cada un año de los tres años desta administraçion y mayordomia, a Anton Ruiz de Baldelomar, presbitero, capellan en la yglesia de Santiago desta çiudad en la capellania que fundo la buena memoria de Françisco de Baldelomar, jurado que fue de Cordova, difunto, la renta del çenso de çinco mill rreales de prinçipal, que yo ynpuse sobre çiertos bienes en fabor de la dicha capellania, que la primera paga que a de pagar a de ser el dia de Todos los Santos primero que berna deste dicho presente año y sucesibe en todo el tienpo desta administraçion, a los plaços del contrato.

Yten el dicho Gaspar Sanchez a de aber y aya por el trabaxo que a de tener en esta mayordomia y administraçion en todo el tienpo de los dichos tres años, sesenta y ocho mill maravedis y questos lo aya e cobre el dicho Gaspar Sanchez Lobo de los mismós frutos, y, en fin de los dichos tres años, el dicho Gaspar Sanchez Lobo a de ser obligado y se obligo de se juntar con el dicho don Luis de Gongora y darle quenta de todos los dichos frutos, haçiendose cargo de los dichos frutos por los rre- 
partimientos del notario de rrentas deçimales y rreçibiendole en descargo las partidas declaradas en esta escritura, y lo que dellas obiere pagado, como costare por las cartas de pago de las dichas personas que las an de aber, y partidas que / no cobrare, como costare por las diligencias hechas contra los deudores por la orden que se declara en esta escritura, y costas y gastos que en el benefiçio desta haçienda obiere fecho, que se an de liquidar como en esta escritura ba declarado, y el dicho su salario todo sacado del dicho cargo, lo demas rrestare en poder del dicho Gaspar Sanchez Lobo, pan, trigo y cebada, maravedis, bino $y$ açeyte $y$ otras qualesquier cosas, con todo ello acudira al dicho don Luis de Gongora, y, pasados los dichos tres años, siendo rrequerido el dicho Gaspar Sanchez Lobo de la dicha quenta de los dichos frutos, dentro de diez dias no la diere, e dicho termino pasado, el dicho Gaspar Sanchez pueda ser y era executado por lo que vbieren balido los dichos frutos, como costare por los testimonios del notario de rrentas, los quales, con el dicho rrequerimiento $y$ esta escritura, sea bastante rrecaudo para la dicha bia executiba, sin que proçeda otra çitaçion, auto ni aberiguaçion, avnque de derecho se rrequiera y, si, lo que Dios Nuestro Señor no quiera ni permita, el dicho don Luis de Gongora falleçiere antes de ser cunplidos los dichos tres años desta mayordomia y administraçion y, a el tiempo de su falleçimiento, el dicho Gaspar Sanchez / Lobo obiere pagado alguna deuda o deudas de las comprehendidas en esta escritura y los frutos que ubiere rreçebido no fueren en la cantidad de de la deuda $y$ deudas que ansi vbiere pagado, y de su salario rratado el tienpo, o, bibiendo, los frutos de todos tres años no balieren las dichas deudas y salario y lo que de las dichas deudas el dicho Gaspar Sanchez obiere pagado o en los dichos frutos, en todos o en parte, el dicho Gaspar Sanchez le fuere puesto algun enbargo o ynpedimiento, de tal manera que çese la cobrança desta mayordomia y administraçion, luego que del costare, el dicho don Luis sea obligado y se obliga de pagar a el dicho Gaspar Sanchez Lobo la cantidad y cantidades que por la dicha rraçon se le debiere, ansi de las deudas declaradas en esta escritura como del dicho su salario rratado. la liquidaçion desta escritura para su execuçion, difirio en ella y en las cartas de pago de las deudas que ubiere pagado de las conprehendidas en esta escritura y el juramento y declaraçion del dicho Gaspar Sanchez Lobo, y anbas partes abran por firme esta carta y cada vno en lo que le toca sin pleyto, so pena del doblo. y para la cobrança de los dichos frutos en todo el tienpo de los dichos tres años / desta administraçion y para dar cartas de pago finiquito y lastro, pareçer en juiçio sobre la cobranca, y hazer los autos pedimientos, rrequerimientos y todos los demas que judiçialmente y extrajudiçialmente conbengan, el dicho don Luis de Gongora a el dicho Gaspar Sanchez Iobo le dio entera mano y bastante poder para efeto de lo contenido en esta escritura; si es necesario, le rrenunçio sus derechos y açiones rreales y personales y executibos $y$, por el dicho tienpo de los dichos tres años, el dicho don Luis de Gongora se obligo de no rrebocar la dicha administraçion y poder; si lo contrario hiçiere, la tal rrebocaçion sea en si ninguna y en todo tienpo se guarde y cunpla lo en esta escritura contenido $y$, para questa escritura tenga mayor balidaçion y efeto, el dicho don Luis de Gongora dixo que rrebocaba $\mathrm{y}$ rreboco qualesquier poder $\mathrm{y}$ poderes espeçiales o generales que aya dado $\mathrm{y}$ otorgado a qualesquier personas para la cobrança de los dichos frutos o qualquier parte dellos, dexando, como dexo, a los dichos procuradores en su honrra e buena fama, y para cunplir esta escritura anbas las dichas partes, don Luis de Gongora e Gaspar Sanchez Lobo, cada vno en lo que les toca, obligaron / sus personas y bienes, abidos y por aber, el dicho don Luis de Gongora, eclesiasticos y seglares, e dieron poder 
a las justiçias que contra cada vno de los dichos otorgantes pueda y deba conoçer ante quien esta carta fuere presentada para que anbos de los dichos otorgantes y cada vno dellos les apremien a su execuçion y guarda e cunplimiento, bien ansi como si fuese por sentençia de juez conpetente, consentida por las partes y pasada en cosa juzgada, rrenunçiaron y apartaron de su fabor y ayuda todas y qualesquier leyes fueros $y$ derechos que en su fabor aya $y$ aber pueda para contrabenir esta escritura y la lei general, rrenunçiaçion de leyes no bala, salbo en lo espresado, y anbas las dichas partes otorgaron esta carta y della dos en vn tenor, una, para el dicho rraçionero don Luis de Gongora, y por otra, para el dicho Gaspar Sanchez Lobo, y para cada rna de las dichas partes la suya ante el escibano publico de Cordova e testigos di yuso escritos, siendo presentes por testigos a el otorgamiento desta carta Luis de Perea, criado del dicho don Luis de Gongora, e Pedro de Bides, que fue procurador del numero de Cordova, e Marcos Ruiz, escrivano que rreside ene ofiçio del escribano diyuso escrito, vecinos y moradores en Cordova / y firmaronlo de sus nonbres los otorgantes en esta escritura de mayordomia, administraçion y poder, a los quales otorgantes yo, el escribano, conozco. D. Luis de Gongora (rubricado) Gaspar Sanchez Lobo (rubricado) Alonso Rodriguez de la Cruz, escribano publico (signado y rubricado) Derechos, cuatro reales.

Archivo de Protocolos de Córdoba.

Oficio, 22

Protocolo, $4^{6}$

Folios, r.670 al r.676

\section{DOCUMENTO NUMERO 5}

Poder otorgado por don Luis de Góngora a favor de Bartolomé Gutiérrez Bustos, para que le cobre los frutos y rentas de la capellanía que poseía en la capilla de San Bartolomé en la iglesia de San Nicolás de la Villa.

Córdoba, i I de Enero de $\times 596$

PODER/Sepan quantos esta carta de poder vieren como yo, Don Luis de Gongora, rracionero en la Santa Yglesia de Cordoba e vecino della en la collacion de santa Maria, capellan de las capellanias que en la yglesia de San Nicolas de la Villa, en la capilla de San Bartolome, que por otro nombre dicen de los Mesas, que dotaron y fundaron la buena memoria de doña Juana de Mesa y Aguilar e Jorge de Mesa, veinte y quatro que fue de la çivdad, y de doña Maria de Mesa, conozco y otorgo que doy todo poder cunplido de derecho bastante a Bartolome Gutierrez Bustos, mercader, veçino de esta çivdad, para que, en mi nonbre y como yo mismo, demande, rresciba y cobre, ansi en juiçio como fue / ra del, de todas e qualesquier personas vezinos desta çivdad y otras partes todos e qualesquier maravedis, pan, trigo, çevada vino, azeyte, abes y otras qualesquier cosas que me son $y$ fueren devidos, perteneçer e perteneçieren por razon de los frutos de las dichas capellanias por contratos de arrendamientos $y$ por los dichos recaudos, $y$, sin ellos, que sean frutos de las dichas capellanias, y de lo que cobrare y rresçibiere y confesare aber cobrado y recibido, dé y pueda dar carta y cartas de pago, reçibo $y$ lastro, chançelo y finiquito, las quales valgan y sean firmes $y$ bastantes como si 
yo las diese y otorgase, $y$, si la paga de lo que rreçiviere, no fuere real, se puede otorgar por entregado e rrenunçiar, que yo renunçio, la ejecucion de la cosa no vista e leyes e derechos de la paga e prueba en la cobrança, parezca en juicio ante qualesquier justicias, y haga los avtos judiçiales y estrajudiçiales, juramentos y diligençias que convengan, para lo qual le doy poder bastante con facultad que le pueda sostituyr, en todo o en parte, en quien quisiere y rrebocallo, e, para lo aber por firme, obligo sus bienes y doy poder a las justicias para su ejecuçion, como cosa pasada en cosa juzgada, fecha e otorgada esta carta en Cordoba, honze / dias del mes de henero de mill e quinientos y noventa y seis años, y firmolo el otorgante, que yo, el escribano, conozco, siendo testigos Gaspar Sanchez Lobo y Francisco de Bargas, bordador, y Pedro de Medina, escrivano, veçinos y moradores de Cordova. D. Luis de Gongora (rubricado) - Alonso Rodriguez de la Cruz, escribano publico (signado $\mathrm{y}$ rubricado) Llevado. Derechos, dos reales.

Archivo de Protocolos de Córdoba.

Oficio, 22

Protocolo, 49

Folio, $4^{8} \mathrm{~V} .^{\circ}$

\section{DOCUMENTO NUMERO 6}

Carta de finiquito otorgada por don Iuis de Góngora y Gaspar Sánchez Lobo, de la administración de los frutos de la prestamera de Santaella que poseía el primero, de dos años.

Córdoba, II de Enero de 1596

FINIQUITO / Sepan quantos esta carta vieren como en la çivdad de Cordova, a honze dias del mes de henero de myll e quinientos e noventa y seys años, otorgaron, de la vna parte, don Luis de Gongora, rraçionero en la Santa Yglesia de Cordova y vecino della, y de la otra Gaspar Sanchez Lobo, mercader, vecino de la dicha çivdad en la collacion de santa Maria, anbas las dichas partes dizeron ques ansi que, por escritura que paso ante el escribano diyuso escripto, en honçe de jullio del año de myll quinientos y noventa y quatro, el dicho don Luis de Gongora encargo y el dicho Gaspar Sanchez Lobo se hiço cargo de administrar los bienes, frutos y rentas perteneçientes al dicho don Luis por razon de la prestamera de la villa de Santaella en tienpo de tres años, que començaron a correr a primero de enero del dicho año de myll e quienientos nobenta y quatro por la forma $y$ orden que se declara en la dicha escriptura, en ejecucion de la qual el dicho Gaspar Sanchez Lobo administro y cobro los frutos de pan, vino, azeyte y menudo perteneçientes al dicho rraçionero por razon de dicha prestamera el dicho año de myll e quinientos e noventa y quatro, que los dichos frutos el dicho año valieron treçientos y honze mill y seteçientos y nueve mara / vedis, con los quales el dicho Gaspar Sanchez Lobo, acudido el dicho don Luis de Gongora y a otras personas por el, de que an fecho y liquidado quentas, y dellos en poder del dicho Gaspar Sanchez no resta ny queda cosa alguna y el dicho Gaspar Sanchez queda pagado de lo que obo de aber por rrazon de la dicha administraçión el dicho año, y anbos otorgantes estan ajustados quel vno al otro y el otro al otro no se rrestan ny queda 
de deber cosa alguna, sobre que, si es neçesario, rrenunçiaron la execvçion de la cosa no vista, leyes y derechos de la paga e prueba y dando como dieron por nynguna la dicha escritura de asiento en quanto a los dos años de noventa e çinco pasado y noventa y seys presente que rrestauan por correr del dicho asiento, se otorgaron el vno al otro distrato de la dicha escritura y finiquito de feneçimiento de quentas bastante de derecho, declarando, como declararon, que de todas las que an tenido hasta oy no se rrestan ny quedan aber el vno al otro ni el otro al otro cosa alguna, lo qual se obligaron de cunplir y aber por firme e no yr contra ello. so es / presa obligaçion que hiçieron de si y de sus bienes y dieron poder a las juscias para su ejecucion y cunplimiento, como por sentencia pasada en cosa juzgada, y otorgaron esta carta y dos en vn tenor, para cada parte la suya, y lo firmaron de sus nonbres los dos otorgantees, que yo, el escribano, doy fe que conozco, siendo testigo Francisco de Bargas, bordador, e Bartolome Gutierrez, mercader, y Pedro de Medina, vecinos de Cordoba. D. Luis de Gongora (rubricado) Gaspar Lobo (rubricado) Alonso Rodriguez de la Cruz, escribano publico (signado y rubricado) Llevado. Derechos, dos reales.

Archivo de Protocolos de Córdoba.

Oficio, 22

Protocolo, 49

Folio, 47

\section{DOCUMENTO NUMERO 7}

Poder otorgado por don Luis de Góngora, a favor de Francisco de Zurita, alférez y vecino de la villa de Cañete, para que pueda cobrar los frutos del beneficio que posela en dicha villa.

Córdoba, 23 de Agosto de 1597

PODER/ Sepan quantos esta carta vieren como yo, don Luis de Gongora, raçionero en la Santa Yglesia de Cordoba e vecino della, conozco e otorgo que doy e otorgo todo mi poder cumplido tan bastante como de derecho se requiere a Francisco de Çurita, alferez e vecino de la villa de Cañete, el mostrador desta, espeçialmente para que, por mi y en mi nonbre e representando mi propia persona, pueda demandar, reçiuir, aver y cobrar, asi en juicio como fuera del, de todas e qualquier personas vecinas de la dicha villa de Cañete e otras partes, todos e qualquier maravedis, trigo, pan çebada, gallinas e otras qualesquiera cosas que me son e fueren debidas, asi del beneficio de la dicha villa que tengo e poseo como en otra qualquier manera y por qualquier causa e rrazon que sea, e de lo que asi reçebiere e cobrare pueda dar e otorgar, de e otorgue carta y cartas de pago, finiquito, cesión, lastro e chancelo y las demas que le fueren pedidas, las quales balgan y sean conformes e balgan como si yo mismo las diese e otorgase, e, sobre la cobranza de los maravedis dichos e de qualquier cosa e parte dello, paresca ante qualquier jueses e jues e haga todas las demandas, pendientes requisitorias e bentas de bienes por escribano e anparo dello y los demas autos y diligençias, judiçiales y estrajudiçiales que cunplan y conbengan e se requieran haçer hasta tanto que la dicha cobranza sea fenecida y acauada, porque cuan cunplido y bastante poder para lo suso dicho 
y lo dello dependiente, quel recibe otro tal y tan cunplido, doy e otorgo al dicho Francisco de Çurita, alferez, con general administracion e facultad de lo poder sustituir en qualesquier personas, y para aber por firme obligo mis bienes e rentas, fecha e otorgada esta carta en Cordoba, a veintitres dias del mes de agosto de mil y quinientos e noventa y siete años, testigos don Alonso de Armenta y don Pedro de Bargas y Bartolome de Morales, vecinos de Cordoba, e firmo de su nombre el dicho otorgante que yo, el escribano, conozco. D. Luis de Gongora (rubricado). Melchor Maldonado, escribano publico (signado y rubricado). Sin derechos.

Archivo de Protocolos de Córdoba.

Oficio, 6

Protocolo 37 , sin foliar cuaderno $3 .^{\circ} \bullet$

\section{DOCUMENTO NUMERO 8}

Escritura otorgada por don Martín de Cárcamo y Mesa como patrono de las capellanias en la iglesia de San Nicolás de la Villa posela don Iuis de Góngora, nombrando capellán de las mismas, a Alonso Gutiérrez de Busto, por renuncia que de ella hizo don Luis.

Córdoba, 2 de Septiembre de ${ }_{597}$.

En la muy noble y muy leal çiudad de Cordova, a dos dias del mes de setienbre de mill y quinientos y noventa y siete años, en presençia de mi, el escribano público de Cordova, y testigos diyuso escriptos, pareció Don Martin de Carcamo y de Mesa, hijo legitimo de don Geronimo de Carcamo y de Mesa, difunto, vecino desta çiudad en la collacion de San Nicolas de la Villa, patrón de las capellanias que doto e fundó, la vna, la buena memoria de Jorge de Mesa, veynticuatro que fue desta çivdad, y la otra, Doña Juana de Mesa y Aguilar, vezinos que fueron desta çvdad, defuntos, y dixo que a su noticia es benido que don Luis de Gongora, rraçionero de la santa Yglesia de Cordoba, vitimo capellan que a sido de las dichas capellanias. hiço desitimiento y dexasçion dellas ante el vicario general desta çivdad y el dicho juez las a auido por baquas, por tanto, vsando del derecho del patronadgo y en la mejor manera que puede y a lugar de derecho, nonbrarua y nombro por capellan de las dichas capellanias a Alonso Gutierrez de Busto, clerigo de menores hordenes, natural desta çivdad, hijo legitimo de / Bartolome Gutierrez Bustos, recino desta çiudad, el qual dicho capellan dixo que presentava y presento ante el hordinario deste obispado para que el dicho Alonso Gutierrez Bustos le sea hecha la colaçion y canonica yntituçión de las dichas capellanias, y consintio se dé por testimonio al dicho Alonso Gutierres para que vse deste nonbramiento, y lo firmo de su nonbre el otorgante, que yo, el escribano, doy fe que conozco, siendo testigos Francisco Lopez, criado del otorgante, e Alonso Cabrera, criado de Don Gonzalo Cabrera, e don Pedro de Medina, escribano de Córdoba. Don Martin de Carcamo i de Mesa (rubricado) - Alonso Rodriguez de la Cruz, escribano publico (signado y rubricado) - Llevado. Derechos, un real.

Archivo de Protocolo de Córdoba.

Oficio, 22

Protocolo, 51

Folio, 500 


\section{- DOCUMENTO NUMFER G}

Escritura otorgada por don Luis de Góngora y Argote, a favor de Gonzalo Fernández de Ahumada, mercader, de cuatrocientos cuarenta y siete reales y tres cuartillos que le debia de ciertos géneros y mercancias que le compró.

Córdoba, 3 de Diciembre de 1597

OBLIGACION $i$. Sepan quantos esta carta vieren como en la çiudad de Córdoba, tres dias del mes de dizienbre de mil y quinientos e noventa y siete años, otorgo don Luis de Gongora y Argote, raçionero en la Santa Yglesia de Cordoba, y vecino della, que deve y se obliga de dar y pagar y dara y pagara a Gonzalo Fernandez de Ahumada, mercader, vecino de la dicha ciudad, que esta avsente, conbiene a sauer, quatroçientos y quarenta y siete reales y tres cuartillos, los quales confeso deuerle y serle obligado a le pagar, los tresçientos e sesenta e ocho reales, de rresto de tosas las mercancias que de la tienda del dicho Gonzalo Fernandez de Ahumada a sacado y lleuado conpradas y de todas quentas hasta oy dicho dia, y los sesenta y nuebe reales y tres quartillos, del preçio de çinco baras y media de paño pardo, a preçio de catorze reales y medio la bara, quel avia, de presente rreçiuio, conprado, de que se dio por entregado, sobre ques en razon de lo suso dicho, renuncio la eçepcion de la cosa no vista, derechos e leies de la paga e prueba della y que, en tiempo alguno, pueda demandar y alegar aquello que dicho es, no fue ni pasa asi, e, si lo dixere o alegare, que no le balga, prometio, e quel obligo de dar y pagar al dicho Gcnzalo Fernandez de Ahumada, o a quien por el fuere parte, los dichosos quatroçientos y quarenta y siete reales y tres quartillos, todos juntos en una paga, el dia de Pascua Florida del año primero benidero de mil y quinientos noventa e ocho, llanamente, so pena del doblo y costas de la cobranza, y, para lo asi cunplir y pagar, obligo sus bienes y rrentas espirituales y temporales, auidos y por aber, y dio poder a las justicias para la ejecucion dello, como por cosa pasada en cosa juzgada, e renuncio las leies de su fauor y la general, y firmo de su nombre el dicho otorgante, que yo, el escribano, conozco, testigos, Gaspar de la Guerra, notario, y Juan de Herrera, estudiante, y Juan Delgado, vecinos y moradores en Cordoba. D. Luis de Gongora (rubricado) Melchor Maldonado, escribano publico (signado y rubricado) Llevado. Sin derechos.

Archivo de Protocolos de Córdoba.

Oficio, 6

Protocolo 37 , sin foliar - cuaderno $3 .^{\circ}$

\section{DOCUMIENTO NUMERO IO}

Escritura otorgada por don Luis de Góngora, don Juan de Góngora y Argote y doña Beatriz Carrillo de los Rłos, su esposa, obligándose a pagar a don Luis de Zúñiga y Bazán, clérigo, dos mil doscientos reales que les habia prestado.

\section{Córdoba, ro de Diciembre de r6o5}

OBLIGACION / Sepan quantos esta carta vieren como nos, don Luis de Gongora, rraçionero de la Santa Yglesia de Cordoba, y don Juan de Gongora y Argote, veinticuatro della, y doña Beatriz Carrillo de los Rios, muger legitima del dicho 
don Juan, vecinos de la dicha çiudad de Cordoba, yo, la dicha Beatriz, en presençia y conliçencia del dicho don Juan de Gongora y Argote, mi marido y señor, que, para otorgar y jurar esta escritura, le pido y demando, e yo, el dicho don Juan, se la doy e conçedo bastante de derecho, y todos los tres susodichos, de mancomun y avoz el vno y cada vno de nos, por si e por todo, rrenunçiando, como rrenunçiamos, los derechos e leyes de la mancomunidad, dinision y escursion, como en ellas y en cada vna dellas se contiene, conoçemos y otorgamos que devemos dar y pagar $y$ daremos y pagaremos a don Luis de Çuñiga Baçan, clerigo residente en esta dicha çiudad, y a quien por el ffuere parte, dos mill y doçientos rreales, que balen setenta y quatro mill y ochoçientos marauedis, los quales conffesamos deberle por raçon de otros tantos que, por nos haçer buena obra, nos a dado prestados en / rreales de contados, de que nos damos por contentos y entregados a toda nuestra boluntad, sobre que rrenunçiamos la esepcion de la no numerata pecunia y los dos años de la prueba de la paga y los otros derechos e leyes que dello tratan, que no nos balan en este caso, por cuia rraçon prometemos y nos obligamos de dar e pagar los dichos dos / mill y doçientos rreales, puestos en la çivdad de Balladolid, a nuestra costa y rriesgo, todos juntos en vna paga en rreales de Plata, sin que ynterbenga moneda de bellon, por el dia de santa Maria de Agosto del año proximo benidero de mill seysçientos y seis, llanamente y sin pleyto alguno, so pena del doblo y costas de la cobrança, e, si al dicho plaço no pagaremos la dicha contia, pueda el dicho don Luis enbiar y enbie a la cobrança della vna persona a nuestra costa, la qual gane de salario, en cada va dia de los que en ella se ocupare en benida, estada y buelta, quinçe, $y$, por lo que montare el dicho salario, seamos executados y apremiados como por el dicho principal, y los dias de la ocupaçion se liquiden con el juramento de la persona en que lo diferimos, e para lo asi cumplir e pagar todos tres debajo de la dicha mancomunidad, obligamos nuestros bienes y rrentas, auidos y por auer, y damos poder a las justiçias, en especial yo, el dicho don Luis de Gongora, lo doy al ilusrisimo señor nuncio de su Santidad que al presente es o ffuere en nuestros rreynos de España y al prouisor y bicario general de la çivdad o villa donde rreside o rresidiere la corte $y$ consejos del rrey nuestro señor, e nos, los dichos don Juan de Gongora y Argote y doña Beatriz Carrillo de los Rios, su mujer, le damos a los señores alcaldes de la casa y corte de su Magestad y corregidor de la ciudad de Balladolid, cuios ffueros e juridicciones nos, los dichos otorgantes, nos sometemos y rrenunçiamos nuestro propio fuero e juridiçion, que al presente tenemos desta dicha çivdad de Cordoba y otro que ganaremos e la ley sid conbenirid juridiçione onible judicun y la nueba prematica, para que las dichas justicias nos conpelan e apremien a la paga e cunplimiento de lo que dicho es, como por cosa pasada en cosa juzgada, rrenunciamos todas y qualquier leyes de nuestra deffensa y ffauor e la ley e derecho, que dice que general rrenunçiaçion no bala, salbo en lo espresado, e yo, la dicha doña Beatriz, rrenuçio el benefficio y leyes de las Partidas y Toro y las demas que son en ffauor de las mugeres, de que ffui auisada por el presente escribano, de lo qual no me ayudare ni aprovechare, e, por casada, juro por Dios e por Santa Maria en fforma de derecho de auer por firme esta carta e no yr contra ella en manera alguna ni pedire ausulucion ni rrelexaçion deste juramento, so pena de perjura, en testimonio de lo qual otorgamos esta carta ante el escribano publico de Cordoba e testigos de yuso escritos, ques fecha e otorgada a diez dias del mes de dicienbre de mill e seysçientos y çinco años, siendo presentes, por testigos, Miguel Hinojosa y Alonso de Iruuque y Francisco de Auila, vecinos de Cordoba y los dichos otorgantes, que 
yo, el escribano, conozco, lo ffirmaron de sus nonbres. D. Luis de Gongora (rubricado) Don Juan de Gongora y Argote (rubricado) Doña Beatriz Carrillo y Rios (rubricados) Melchor Maldonado, escribano publico (signado y rubricado). Llevado.

Archivo de Protocolos de Córdoba.

Oficio, 6

Protocolo, 42, sin foliar, cuaderno, $\mathrm{n}^{\circ}{ }^{\circ}$

\section{DOCUMENTO NUMERO II}

Poder otorgado por don Luis de Góngora, racionero en la Santa Iglesia de Córdoba, a favor de su sobrino don Luis de Saavedra, para recibir en arrendamiento, de por vida, unas casas en la plazuela del Convento de la Trinidad.

Córdoba, I6 de Febrero de 1612

Sepan quantos esta carta bieren como yo, don Luis de Gongora, racionero en la Santa Yglesia de Cordoua, vecino de la dicha çiudad de Cordoua, otorgo e conozco que doy mi poder cunplido, tan bastante como de derecho se rrequiere, a don Luis de Saabedra, mi sobrino, asimismo rraçionero en la dicha Santa Yglesia, espeçialmente para que, en mi nonbre, pueda rreçibir y rreçiba en arrendamiento, de por bida, de los señores Dean e Cabildo de la Santa Yglesia desta ciudad, vnas casas que son en esta ciudad, en la plaçuela del conbento de la Santisima Trinidad, que bacaron por muerte de Juan de Mora, presbitero, las quales rreçiba por los dias y años de mi bida y por los dias y años de la bida del dicho don Luis de Saabedra, mi sobrino, para pagar de rrenta, cada vu año, treynta y siete mill e quinientos marauedis y treynta e siete pares y medio de gallinas, para lo pagar a los plazos que sentare, y çerca dello hago y otorgo la escritura y escrituras que conbengan con las fuerças, binculos y firmezas, clavsulas y condiçiones, penas y posturas y pribaciones que sean necesarias y sigun se Reclara en la postura que del dicho dio de por bida, e fecho que, de la forma y manera que el dicho don Luis de Saabedra hiçiere y otorgare la dicha escritura, yo, por la presente, la otorgo y me obligo de cunplir e pagar lo que en ella contenido, so las penas que en mi nonbre pusiere, que para ello le doy poder bastante con general ad/ministraçion, y para estar y aber por firme este poder y lo que, por birtud del, fuere fecho, obligo mis bienes y rrentas, auidos y por aber, y doy poder a las justicias para su ejecucion e cumplimiento, como por cosa sentençiada pasada en cosa juzgada, que es fecha e otorgada esta carta en Cordoua, dies $y$ seis dias del mes de hebrero de mill e seisçientos e doze años, siendo presentes por testigos Anton de Baena y Bartolome de Olmedo y Rodrigo Fernandez, escribano de S. M. vecinos de Cordoua y firmolo el otorgante, que yo, el escribano, doy fee que conozco. D. Luis de Gongora (rubricado). Agustin de San Juan / escribano publico (rubricado). Debense los derechos (rubricado).

Archivo de Protocolos de Córdoba.

Oficio, 43

Protocolo, 42

Folio 124 Vt. ${ }^{\circ}$ 